\title{
BMJ Open Descriptive study of workplace demand, control and bullying among migrant and Australian-born workers by gender: does workplace support make a difference?
}

\author{
Alison Reid (D) , ${ }^{1}$ Alison Daly (D) , ${ }^{1}$ Anthony D LaMontagne, ${ }^{2}$ Allison Milner, ${ }^{3}$ \\ Elena Ronda Pérez ${ }^{4,5}$
}

To cite: Reid A, Daly A, LaMontagne AD, et al. Descriptive study of workplace demand, control and bullying among migrant and Australianborn workers by gender: does workplace support make a difference? BMJ Open 2020;10:e033652. doi:10.1136/ bmjopen-2019-033652

- Prepublication history and additional material for this paper are available online. To view these files, please visit the journal online (http://dx.doi. org/10.1136/bmjopen-2019033652).

Allison Millner died suddenly last year - we wish to retain her as an author on this paper

Received 15 August 2019 Revised 22 April 2020 Accepted 29 May 2020

Check for updates

(C) Author(s) (or their employer(s)) 2020. Re-use permitted under CC BY-NC. No commercial re-use. See rights and permissions. Published by BMJ.

For numbered affiliations see end of article.

Correspondence to

Dr Alison Reid;

alison.reid@curtin.edu.au

\section{ABSTRACT}

Objective The objective of this study is to examine the relationship between bullying in migrants and Australians and types of workplace lso-strain, by gender.

Design and setting Two descriptive cross-sectional surveys of the Australian working population.

Participants Australian-born workers of Caucasian ancestry $(n=1051$, participant response rate $=87.3 \%)$ and workers born in New Zealand $(n=566)$, India $(n=633)$ and the Philippines $(n=431)$ (participant response rate $=79.5 \%)$. Primary and secondary outcomes measures Using logistic regression, we examined whether self-reported assessment of various forms of bullying in the workplace was associated with Iso-strain (job with high demands and low control and without social support), gender and migrant status.

Results The prevalence of workplace bullying within the previous year was $14.5 \%$. Sexual harassment, though rare $(\mathrm{n}=47,1.8 \%)$, was reported by more women than men $(83 \%$ vs $17 \%, \chi^{2}=19.3, p<0.0001$ ) and more Australia or New Zealand born workers compared to India or the Philippines workers $\left(75.5 \%\right.$ vs $\left.25.5 \%, \chi^{2}=4.6, p=0.032\right)$. Indian-born women had lower adjusted OR for being bullied and for being intimidated compared to other women. Independent of migrant status, Iso-strain (1), (low support from boss) and Iso-strain (2), (low support from colleagues) predicted being bullied. Women were more likely to be in an Iso-strain (1) job than men $(18.7 \%$ vs $13.6 \%, p=0.013)$ and had twice the risk of being both verbally abused and intimidated compared to men (OR 9 vs OR 5.5, $p<0.0001$ ).

Conclusion Workplace bullying was more likely for women than men. There were few differences between workers from different migrant groups. Iso-strain was the strongest predictor of workplace bullying. Workplaces should encourage supportive and collegiate work environments.

\section{INTRODUCTION}

Exposure to workplace psychosocial stressors differs by migration status and gender. ${ }^{1}$ Compared to native-born workers, migrants have a higher prevalence of exposure to most psychosocial stressors, including high demands,
Strengths and limitations of this study

- With increasing burden in primary care, knowledge of target groups and specific situations that contribute to illness can inform interventions to eliminate or reduce the problems thereby reducing burden on healthcare.

- We used previously validated and reliable questions to assess bullying and high strain employment.

- Investigating minority groups can assist in targeting programmes to address potential problems which negatively impact health

- Cross-sectional design does not allow causal conclusions; the self-report nature of the study can lead to an overestimation bullying and working in isolation in high demand jobs; respondents were not asked if they thought bullying was racially motivated and this may have lead to an underestimation of racial bullying.

lower job control ${ }^{2}$ and less social support. ${ }^{3}$ Women are more exposed to emotional job demands, lower job control and lower reward, than men. ${ }^{4}$

High job strain, the combination of high job demand and low job control is associated with both physical and mental health issues. ${ }^{5}$ Some studies of exposure to high job strain hypothesised that high job strain might encourage conditions in which a worker has an increased risk for becoming a target of bullying, ${ }^{6}$ while other research found it did not. ${ }^{7}$ Iso-strain is a psychosocial workplace hazard that is based on two conditions, first the worker is in a high strain job (a job with high demands and low control as defined by Karasek et $a l^{8}$ and second that the worker has little or no workplace support from either colleagues or supervisors. ${ }^{9}{ }^{10}$ Isostrain has been associated with higher risk of cardiovascular disease, ${ }^{11}$ absence from work for 
mental health issues, ${ }^{12}$ decreased emotional and physical functioning in women ${ }^{13}$ and various self-reported physical symptoms. ${ }^{14}$

Bullying is associated with the presence of poor working conditions including high workload, low control and job insecurity. Bullying can take different forms; sexual harassment, intimidation, verbal or physical abuse and the type of bullying and the perpetrator are important issues to consider when estimating its prevalence. ${ }^{15} 16$ Sexual harassment is more likely for those in precarious employment especially for women. ${ }^{17}$ Bullying as a workplace stressor has been associated with a range of adverse health outcomes, in particular, anxiety, irritability and depression. ${ }^{18}$ There has been little investigation into the association between Iso-strain and bullying, however one study showed that increasing likelihood of being bullied during high stress situations is increased when social support is low $^{19}$ and another showed that Iso-strain interacted with the effect of being bullied. ${ }^{6}$

While some research has shown that the likelihood of being bullied in the workplace is similar for men and women ${ }^{720}$ the response to bullying appears to be different. Men tend to leave the workplace while women stay but have more absenteeism. ${ }^{21}$ Men were more likely to have a common work mental disorder than women. ${ }^{22}$ Men and women tend to do very different jobs ${ }^{4}$ which may explain differences in responses to psychosocial hazards such as bullying.

Research examining both racism and bullying is limited and there is little empirical data about differentials in bullying between ethnic and racial groups. Among White, African American, Hispanic/Latino workers the latter group were more likely to report general bullying, while all non-Caucasian groups were likely to report racial or ethnic bullying. ${ }^{2}$ In the UK, ethnic minority workers in the public sector were more likely to be bullied than their white counterparts. ${ }^{23}$ However, we were unable to find work examining bullying in workers born outside the host country who migrated for work, despite the likelihood of their being a vulnerable group. ${ }^{24}$

In 2016, 35\% of Australian workers were born overseas. ${ }^{25}$ Most of these entered Australia as skilled workers, based on their educational and occupational qualifications, and in the last 10 years the majority of skilled workers came from India, China, the UK and the Philippines. ${ }^{26}$ However, the largest migrant group in Australia after the UK come from New Zealand and do not need skills or qualifications to enter and work in Australia. ${ }^{25}$

The aims of this current study are to describe the prevalence and type of bullying by gender for Australian born workers and three migrant groups, workers born in New Zealand, India and the Philippines; to compare men and women within the three migrant groups; and to determine if Iso-strain is associated with bullying among these groups.
MATERIAL AND METHODS

\section{Study design}

Two national, cross-sectional telephone surveys, conducted in 2017-2018, targeted Australian-born workers aged 18-65 years of Caucasian origin and migrant workers born in New Zealand, India and the Philippines, $(8.7 \%, 7.8 \%$ and $3.9 \%$ of the working migrant population, respectively). ${ }^{27}$

\section{Participants}

The Australian worker study used the Electronic White Pages (EWP), including both land line and mobile telephone numbers where these were listed, to call a randomly selected total of 33103 households of which 1217 contained eligible respondents and 1062 consented to participate (participation rate $87.3 \%$ ).

The migrant worker survey required a variety of methods to obtain enough sample: the first was a random sample of the EWP filtered by the most common surnames for peoples born in the target countries; the second targeted only suburbs that had high proportions of the target migrant residents; the third used a commercial sampling firm and the fourth used snow ball sampling. Using these four methods a total of 310636 households were called of which 2051 had eligible respondents and 1630 consented to participate (participation rate $79.5 \%$ ). Full details of the methods have previously been published. ${ }^{28}$

\section{Variables}

Trained interviewers used computer-assisted telephone interviews to collect data. Migrant participants were given the option of completing the interview in Hindi or Tagalog. Information collected included gender, age, country of birth, year of arrival in Australia, highest level of education, employment status, contract type, occupation (coded using the Australian and New Zealand Standard Classification of Occupations), ${ }^{29}$ bullying and racial discrimination. The definition of bullying was being bullied within the last year in one of three ways. Discrimination was whether or not the respondent had ever been racially discriminated against by anyone. Being in a high strain job was whether or not the respondent was in a job with high demand and low control. Iso-strain was defined as being in a high strain job and having little or no support at work from either supervisor (Iso-strain(1) or colleagues (Iso-strain (2)). (See online supplementary table 1 for details on how bullying, racial discrimination, job strain and Iso-strain were assessed.)

\section{Patient and public involvement}

The questionnaire was informed by previous validated research without direct involvement of the respondents. There was no public involvement in this study. Respondents were asked if they would be willing to participate before the interview proceeded.

\section{Statistical analysis}

Only participants who had been bullied within the last year were included in the analysis. To enable comparable 
descriptive estimates, data from the survey were weighted using Iterative Proportional Fitting with age, gender, education and area of residence for each migrant group surveyed using the 2016 Australian Bureau of Statistics Census data. ${ }^{27}$ Univariate descriptive analysis produced weighted estimates with 95\% CIs for sociodemographic, employment variables, job strain, social support, being bullied and racial discrimination by migrant status. Adjusted ORs were calculated for the prevalence of workers who reported being bullied adjusted for age, education, years in Australia, employment status, contract type and occupation. Stratified logistic regression (by sex) was used to develop models related to being bullied using the variables in the univariate analysis as covariates in conjunction with job strain and Iso-strain (job strain (high demand/low control) with little support from (1) supervisors or (2) colleagues. Logistic regression was used to develop models for ever been bullied, bullied within the previous year, feeling safety or health at work was at risk due to bullying and experiencing both racial discrimination and bullying. Deletion of non-significant covariates $(p>0.05)$ was used to improve all models. Only statistically significant associations were reported. Post estimation tests were conducted for fit using contrast Hosmer-Lemeshow $\chi^{2}$ for logistic models and Bayesian information criteria to identify the models with the best fit for the data ${ }^{30}$ with level of fit determined by using the Raftery criteria. ${ }^{31}$ All analyses were conducted using Stata V.14.

\section{RESULTS}

There were significant differences across almost all of the sociodemographic and work-related variables between the workers by country of birth (table 1). Only perceived support from supervisors or colleagues among women and men did not differ by country of birth.

Overall, the prevalence of job strain was significantly higher among women than men $\left(34.6 \%\right.$ vs $27.5 \%, \chi^{2}=8.3$, $\mathrm{p}=0.004$; data not shown) as was Iso-strain (1) (18.7\% vs 13.6, $\chi^{2}=6.2, \mathrm{p}=0.013$; data not shown). There was no statistically significant difference in Iso-strain (2) between women and men $\left(15.5 \%\right.$ vs $12.8 \%, \chi^{2}=1.5, p=0.219$; data not shown).

The prevalence of job strain, Iso-strain (1) and Isostrain (2) did not vary by country of birth among men (table 2). Compared to men, the prevalence of job strain was higher in women born in Australia or India. The prevalence of Iso-strain (1) was also higher among Australian women compared to their male counterparts, and the prevalence of Iso-strain (2) was higher among Indianborn women compared to their male counterparts.

Across women and men combined, 771 (weighted prevalence $27.1 \%$ ) reported having ever been bullied in the workplace at any time. Women were more likely to report ever having been bullied as were workers born in New Zealand, workers with education higher than school and workers aged over 45 years. However, the highest odds of reporting ever being bullied were workers who had any type of Iso-strain (OR 1.8 (1.3 to 2.4), p<0.0001). Full results are shown in online supplementary table 2 .

When being bullied within the previous 12 months in one of three ways, sexually harassed, verbally abused or intimidated was examined by gender, women born in India had statistically significantly lower adjusted prevalence ratios for being bullied overall or for being intimidated in the previous 12 months compared to women born in Australia, New Zealand or the Philippines (table 3). A higher per cent of women than men reported being bullied within the previous 12 months across all types of bullying, and these differences were statistically significant. A higher per cent of Filipino women reported being verbally abused although the CI around this estimate overlapped with the other migrant groups. Australian-born women reported their health/ safety was at risk due to bullying compared to Filipino and Australian-born men, respectively. Full results are shown in online supplementary table 3 .

Across men and women combined, 356 workers (weighted prevalence $14.5 \%$ ) reported being bullied within the previous 12 months. When sex was used as a covariate, women were more likely to report being bullied within the last year (OR 1.9, 95\% CI (1.4 to 2.5), $\mathrm{p}<0.0001)$ as were people with education higher than school and those who worked for others. The highest odds of being bullied in the last 12 months were those who had any type of Iso-strain (OR 6.1, 95\% CI (4.6 to $8.1), \mathrm{p}<0.0001)$. There was no statistically significant association with country of birth. Full results are shown in online supplementary table 4 .

When men and women were analysed separately, country of birth was also not a significant predictor of bullying in the last year after adjusting for all the covariates in tables 1 and 2. Other than Iso-strain (1) and (2), only education significantly predicted risk of bullying. However, there were differences by gender and type of Iso-strain. The risk of being bullied within the previous 12 months was six times more likely if the worker had any kind of Iso-strain job (table 4). Men with a trade/diploma or certificate educational qualification had a higher likelihood of being bullied compared to any other education level. Women in an Iso-strain one job were almost six times more likely to be bullied compared to women not in Iso-strain (1) jobs. This increased to nine times the likelihood of being bullied if women were in an Iso-strain (2) job.

Education level was the only sociodemographic variable that significantly increased the risk of being verbally abused, intimidated or both, for men and women (table 5). Iso-strain was the biggest predictor of any form of bullying, independent of gender.

The prevalence of racial discrimination was low $(n=208$, weighted prevalence $7.5 \%$ ) but almost a quarter who reported racial discrimination $(\mathrm{n}=72$, weighted prevalence $23.8 \%$; data now shown) also reported being bullied in the last year. After adjusting for sociodemographics and 


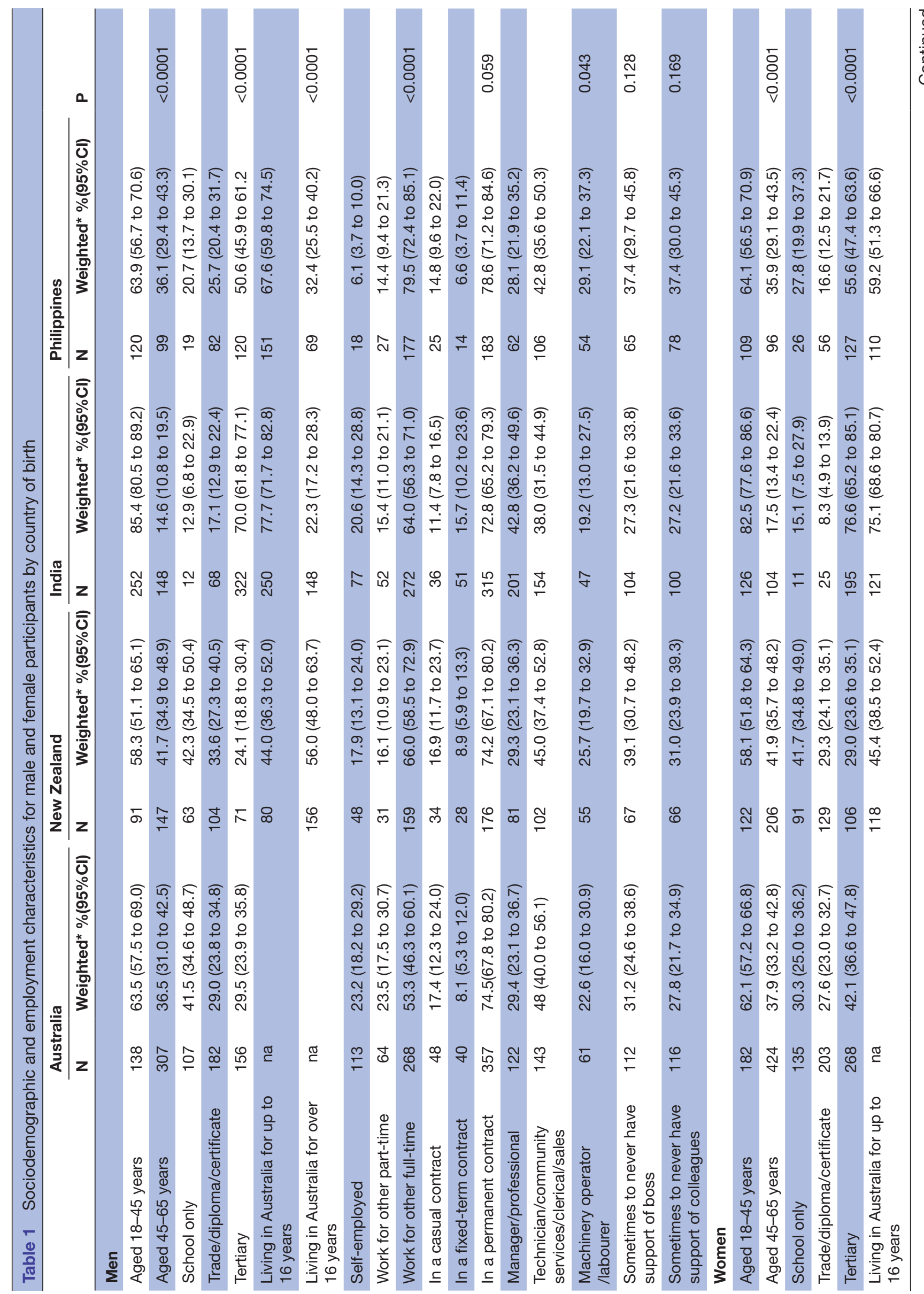




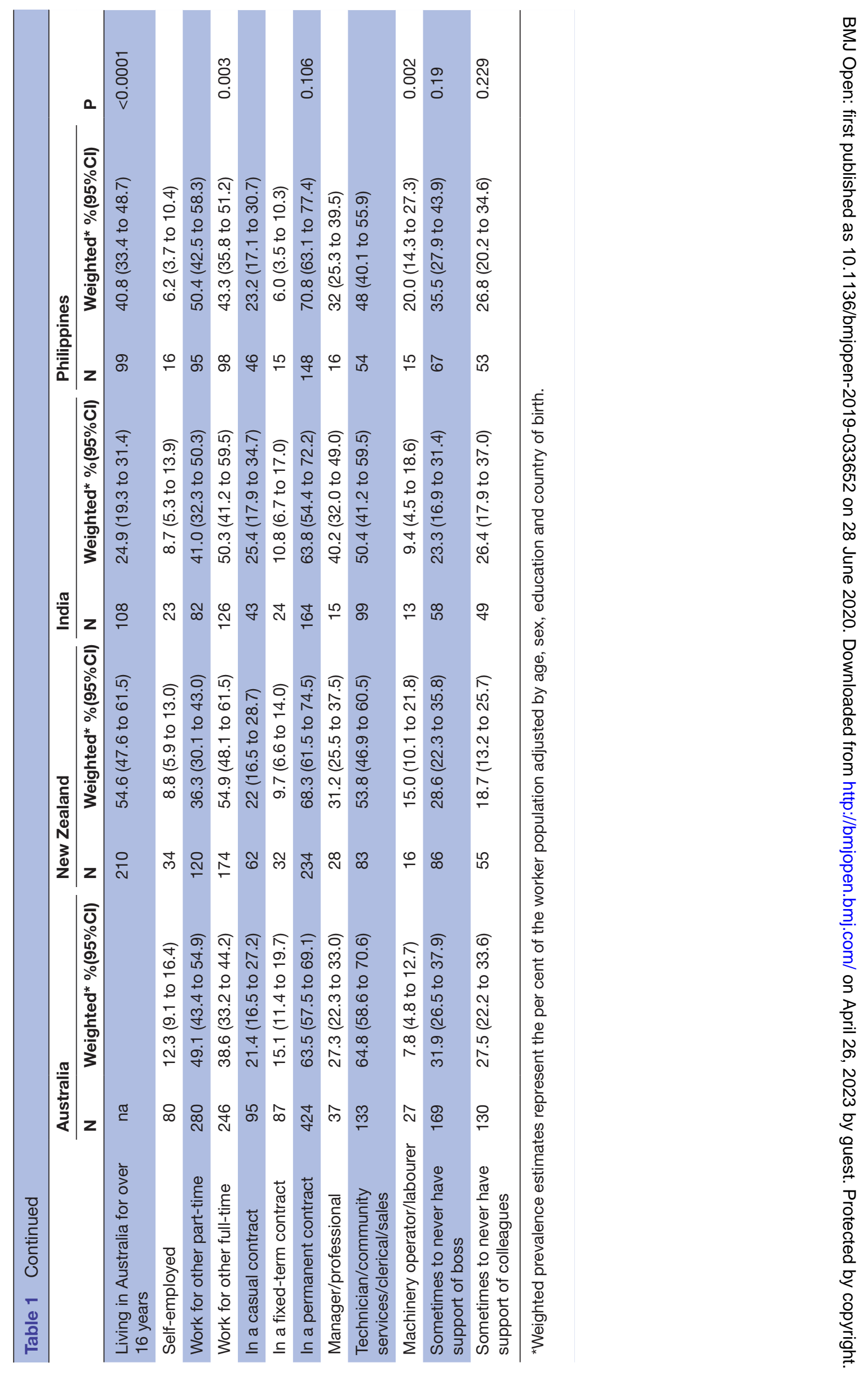


Table 2 Prevalence of job strain, Iso-strain (1) and Iso-strain (2) in workers born in Australia and New Zealand, India and the Philippines, by gender

\begin{tabular}{|c|c|c|c|c|c|c|c|c|c|}
\hline & \multicolumn{2}{|c|}{ Australia } & \multicolumn{2}{|c|}{ New Zealand } & \multicolumn{2}{|c|}{ India } & \multicolumn{2}{|c|}{ Philippines } & \multirow[b]{2}{*}{$\mathbf{P}$} \\
\hline & $\mathbf{N}$ & $\begin{array}{l}\text { Weighted* \% } \\
\text { (95\% Cl) }\end{array}$ & $\mathbf{N}$ & $\begin{array}{l}\text { Weighted* \% } \\
\text { (95\% Cl) }\end{array}$ & $\mathbf{N}$ & $\begin{array}{l}\text { Weighted* \% } \\
(95 \% \text { Cl) }\end{array}$ & $\mathbf{N}$ & $\begin{array}{l}\text { Weighted* \% } \\
\text { (95\% Cl) }\end{array}$ & \\
\hline Job strain & 117 & 28.2 (22.2 to 35.2$)$ & 49 & 24.8 (18.4 to 32.6$)$ & 111 & 25.0 (19.9 to 30.9$)$ & 64 & 31.3 (24.6 to 38.9 ) & 0.515 \\
\hline $\begin{array}{l}\text { Iso-strain (1) } \\
\text { supervisor }\end{array}$ & 46 & 10.8 (7.6 to 15.1$)$ & 25 & 15.0 (9.6 to 22.7 ) & 57 & 11.5 (8.3 to 15.8 ) & 30 & 19.7 (13.5 to 27.8$)$ & 0.065 \\
\hline \multicolumn{10}{|l|}{ Women } \\
\hline Job strain & 231 & $38.8^{\star *}(33.4$ to 44.6$)$ & 99 & 29.9 (24.0 to 36.6) & 79 & $40.0^{\star \star}(30.9$ to 49.9$)$ & 55 & 27.8 (21.0 to 35.8$)$ & 0.037 \\
\hline $\begin{array}{l}\text { Iso-strain (1) } \\
\text { supervisor }\end{array}$ & 99 & $22.3^{* *}$ (17.3 to 28.3$)$ & 43 & 15.4 (10.7 to 21.6$)$ & 31 & 18.5 (12.2 to 27.1$)$ & 27 & 16 (10.4 to 23.8) & 0.254 \\
\hline
\end{tabular}

${ }^{* *} \mathrm{P}<0.05$ for differences between women and men in the same country of birth group.

*Weighted prevalence estimates represent the per cent of the worker population adjusted by country of birth. Iso-strain (1) combination of job strain +lack of support from supervisor. Iso-strain (2) job strain +lack of support from colleagues.

working conditions, there were no gender differences in the likelihood of experiencing both bullying and discrimination. There was over a twelve-fold increase in the likelihood of experiencing both bullying and discrimination if the worker was born outside Australia and over twice the likelihood of experiencing both if the worker was also in any Iso-strain job (online supplementary table 5).

\section{DISCUSSION}

In this study examining bullying at work among Australianborn workers and migrant workers to Australia, the prevalence of bullying (14.5\%) within the last 12 months was similar compared to other estimates using the same type of measure $(14.8 \%){ }^{32}$ There were no differences by country of birth in either men or women after adjusting for employment and sociodemographic characteristics. Neither job strain nor category of Iso-strain varied significantly in men by country of birth. Australian and Indianborn women reported more job strain and Australian-born women more Iso-strain (1) than the other groups.

The prevalence of all types of bullying was higher in women than men. Working with job strain and without support from either supervisors or colleagues were significant predictors of being bullied in both men and women, with risks tending to be higher in women. Bullying also impacted adversely on health and safety at work, particularly for women and those working with job strain and without support from supervisors and/or colleagues. Iso-strain jobs were related to an increased likelihood of experiencing both racial discrimination and bullying in the previous year.

In this current study, we found differences between women and men in the prevalence of job strain, Iso-strain
(1), Iso-strain (2). In general, the prevalence of these exposures was higher in women than men within country of birth groups as well as overall. This concurs with work from Canada that found that women were more likely than men to be in high strain jobs $(25.7 \%$ v $16.2 \%$, respectively), and to be in high strain jobs with low support ( $16.8 \%$ v $11.0 \%$, respectively), although the latter difference was not statistically significant. ${ }^{33}$ In the European Union, women's jobs are more monotonous, demanding and lower paid with fewer promotion prospects than men. They also experience more psychological and sexual harassment. ${ }^{34}$ A meta-analysis of studies published between 1999 and 2010 comparing working conditions between women and men found inconsistency in exposure to psychosocial stressors. More men were exposed to low support at work and more physically demanding work than women, while more women worked in high demand low control jobs and on a temporary contract or in shift work. ${ }^{4}$

The prevalence of bullying in this current study was similar to other studies, both from Australia and internationally. SafeWork Australia reported a prevalence of $9.7 \%$ in a representative sample of the Australian working population in $2014 .^{35}$ In Europe ${ }^{36}$ and the USA, ${ }^{37}$ the prevalence of workplace bullying ranged between $10 \%$ and $15 \%$ depending on the definition of bullying used. ${ }^{38}$ In a study of migrant workers in Australia, the prevalence of bullying, which was operationally defined, was lower $(12 \%)$ than found in this current study ${ }^{1}$ but similar to other research $(13 \%)$ where a definition was given. ${ }^{20}$

Bullying has been described as being gendered, with men more likely to be bullied by other men and women most likely to be bullied by men but also bullied by 


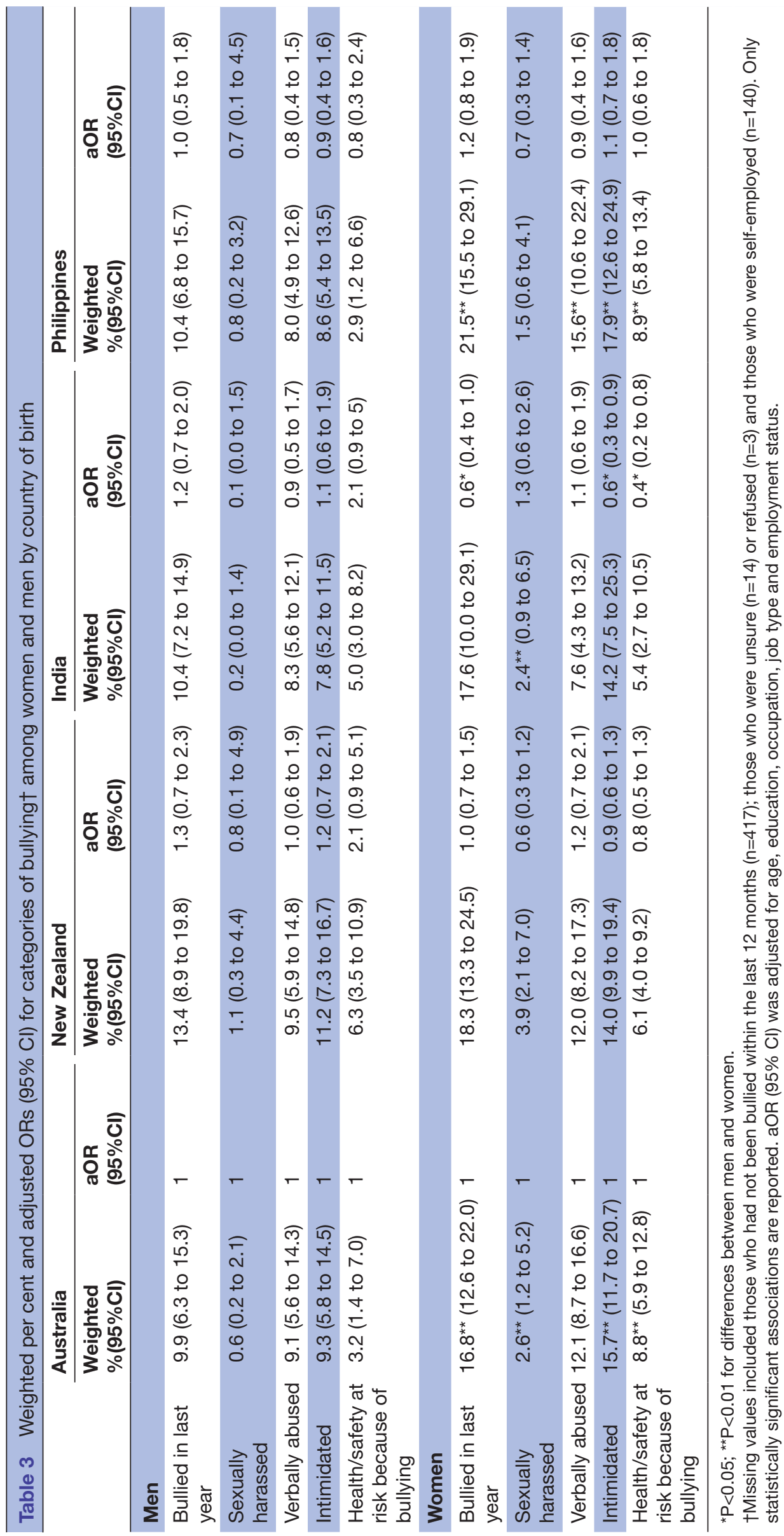


Table 4 Likelihood of being bullied in the last 12 months, for men and women, adjusted

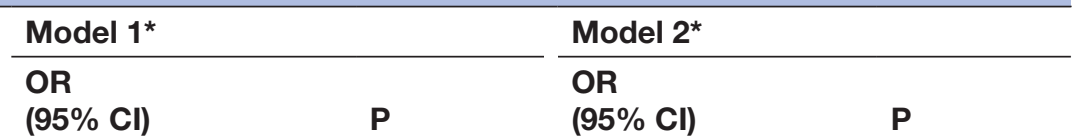

\begin{tabular}{|c|c|c|c|c|}
\hline \multicolumn{5}{|l|}{ Men } \\
\hline $\begin{array}{l}\text { Having a trade/diploma/certificate qualification vs } \\
\text { any other education qualification }\end{array}$ & 3.1 (1.8 to 5.3 ) & $<0.0001$ & 3.2 (1.9 to 5.5$)$ & $<0.0001$ \\
\hline Iso-strain (2) & & & 6.1 (3.5 to 10.8$)$ & $<0.0001$ \\
\hline \multicolumn{5}{|l|}{ Women } \\
\hline Iso-strain (1) & 5.8 (3.5 to 9.5$)$ & $<0.0001$ & & \\
\hline Iso-strain (2) & & & 9.1 (5.0 to 16.6$)$ & $<0.0001$ \\
\hline
\end{tabular}

${ }^{*}$ Adjusted for age, occupation, job type, employment status.

women. ${ }^{39}$ Women are more likely to report behaviours such as emotional abuse ${ }^{40}$ as well as condescension and public disparagement compared to men. ${ }^{41}$ In our study we found the prevalence of overall bullying was higher in women than men. While this finding has been reported elsewhere, ${ }^{42}$ it is not a consistent finding, which may be due to differences in the definition of what constitutes bullying. In the study where no gender differences were found, bullying was defined by duration and frequency of being hassled, unjustly criticised or 'shown up in front of other' within the last 6 months. Our study used a broader definition of whether or not the participant had experienced one of three types of bullying (sexual harassment, intimidation or verbal abuse) within the previous 12 months.

We also found that the prevalence of specific types of bullying, for example, intimidation, was higher in women than men. In particular sexual harassment, while not common, was much more likely to be reported by women which was similar to that found in previous work

Table 5 Likelihood of being verbally abused, intimidated or both for men and women

\begin{tabular}{|c|c|c|c|c|c|c|}
\hline & \multicolumn{2}{|c|}{ Being verbally abused* } & \multicolumn{2}{|c|}{ Being intimidated } & \multicolumn{2}{|c|}{$\begin{array}{l}\text { Both verbally abused and } \\
\text { intimidated }\end{array}$} \\
\hline & OR (95\% Cl) & $\mathbf{P}$ & OR (95\% Cl) & $\mathbf{P}$ & OR (95\% Cl) & $\mathbf{P}$ \\
\hline $\begin{array}{l}\text { Trade/diploma/certificate vs } \\
\text { school only }\end{array}$ & 2.8 (1.5 to 5.0$)$ & 0.001 & 3.6 (1.6 to 8.2$)$ & $<0.0001$ & $3.4(1.4$ to 8.3$)$ & 0.007 \\
\hline Tertiary vs school only & & & 1.4 (0.6 to 3.0) & 0.037 & 1.3 (0.5 to 3.0$)$ & 0.579 \\
\hline Iso-strain (2) $\dagger$ & 5.5 (3.0 to 9.9$)$ & $<0.0001$ & 5.3 (3.0 to 9.5$)$ & $<0.0001$ & 5.5 (2.9 to 10.3$)$ & $<0.0001$ \\
\hline \multicolumn{7}{|l|}{ Women } \\
\hline $\begin{array}{l}\text { Trade/diploma/certificate } \\
\text { compared to any other level of } \\
\text { education }\end{array}$ & 1.6 (0.9 to 2.7$)$ & 0.082 & 2.7 (1.3 to 5.6) & $<0.0001$ & 4.0 (1.8 to 8.8$)$ & 0.001 \\
\hline Iso-strain (2)† & 6.9 (3.8 to 12.7$)$ & $<0.0001$ & 9.4 (5.3 to 16.7$)$ & $<0.0001$ & 9.6 (5.1 to 18.2$)$ & $<0.0001$ \\
\hline
\end{tabular}

*Adjusted for age, occupation, job type, employment status; using Bayesian Information Criteria, model 2, Iso-strain (2) fit the data better than model 1, Iso-strain (1) (difference in BIC of 4.6 provides positive to strong support for model 2). ${ }^{31}$ While there were minor differences in the ORs for education between men and women, they were so small that only the model for men was used to enable a comparison between the types of Iso-strain.

†Being in an Iso-strain (2) was a better fit for the data, compared to being in an Iso-strain (1) job for all types of bullying with the BIC difference ranging from 6.0 (strong support) for verbally abused to 8.1 (strong to very strong support) for being both verbally abused and intimidated. ${ }^{31}$ 
in Australia although we did not find the same the strong association with casual employment. ${ }^{17}$

While there were no statistically significant differences for the likelihood of being bullied by country of birth in either men or women after adjusting for occupation and demographic characteristics, unadjusted estimates in the types of bullying did differ by both gender and country of birth. This discrepancy might be due to the relatively small numbers who reported being bullied but this would need to be further investigated. The current study suggests that it is demographic and/or occupational characteristics that predict bullying and not gender or country of birth per se.

Working in a job that was demanding as well as lacking in support from either a supervisor or colleague (Isostrain) was the biggest predictor of bullying in our study. Workers in these types of jobs reported a 5 -fold to 10 -fold increased risk of being bullied compared to workers not working in Iso-strain jobs. Similar findings have been reported among employees working in a range of occupations in the USA, ${ }^{6}$ and among Australian frontline police officers where bullying increased as job demands increased and support and job control decreased..$^{19}$ In the current study, lack of support from a colleague offered a better fit for the data than the lack of support from a supervisor. This might be a factor specific to Australian workers and workplaces, where the ideas of egalitarianism and 'mateship' are important cultural phenomena.

Another possible explanation for the relationship between iso strain and workplace bullying may be that not having support is, itself, part of the bullying. It is also possible that multiple forms of discrimination may be happening across a variety of situations. ${ }^{6}$ Some research suggests that the combination of these factors lead to lack of engagement within the workplace. ${ }^{43}$ Further investigation investigating the interactions and associations between measures of workplace psychosocial stressors is planned.

The lack of association between bullying and any employment characteristics, which had been previously reported as strongly associated, ${ }^{44}$ may be indicative of a changing workplace environment ${ }^{45}$ as more people are moving from traditional work arrangements to more flexible work arrangements. ${ }^{46}$ This requires further investigation.

Our cross-sectional surveys depended on self-report for key variables such as bullying. However, the consistency of our results with previous research provides some support for our estimates. A further limitation of our study was the use of three sampling methods: electronic telephone books which offered a reasonable platform for random sampling but lacked full mobile contact information; sample brokers who had mobile numbers but provided information from unknown sources; and snowball sampling, limiting their generalisability. Weighting the data to the census for workers from each migrant group reduced bias in prevalence estimates and improved the generalisability of our findings. We did not specifically ask respondents if they thought bullying was occurring because of their race or if they had experienced physical violence. These omissions might have led to an underestimation of bullying. We also did not ask income which precluded any analysis to examine economic status and bullying.

\section{CONCLUSION}

This study provides the first population-based investigation of work place bullying in migrant groups by gender. While there were no statistically significant differences in the prevalence of bullying by migrant status, women overall and in the target countries of birth were more likely to be bullied at work than their male counterparts. Iso-strain, whether driven by lack of support from supervisors or colleagues, was the strongest predictor of bullying in the workplace. As a consequence, workplaces should encourage supportive and collegiate work environments as well as reducing high job strain as means of preventing or mitigating bullying. Specific policies to address gender and migrant status issues need to be developed in conjunction with those groups as a matter of priority.

Author affiliations

${ }^{1}$ School of Public Health, Curtin University Bentley Campus, Perth, Western Australia, Australia

${ }^{2}$ Population Health Strategic Research Centre, School of Health \& Social

Development, Deakin University, Melbourne, Victoria, Australia

${ }^{3}$ School of Population and Global Health, University of Melbourne, Melbourne,

Victoria, Australia

${ }^{4}$ Preventive Medicine and Public Health Area, University of Alicante, Alicante, Alicante, Spain

${ }^{5}$ Centre for Research in Occupational Health (CISAL), Universitat Pompeu Fabra, Barcelona, Barcelona, Spain

Acknowledgements The authors would like to thank the Edith Cowan University Survey Research Centre who conducted the surveys on our behalf.

Contributors AR initiated the study. AD, AR and ERP contributed to the planning and design. $A R$ and $A D$ contributed to the development of questions. $A D$ and $A R$ drafted the manuscript, $A D, A R, A D L, A M$ and ERP revised it. All authors read and approved the final manuscript.

Funding The project was funded by the Australian Research Council Discovery Project \#DP160100660.

Competing interests None declared.

Patient consent for publication Not required.

Ethics approval Human Research Ethics Committee of Curtin University (HREC RDHS-55-16).

Provenance and peer review Not commissioned; externally peer reviewed.

Data availability statement Data are available upon reasonable request. Application for data accompanied by appropriate ethics information can be made to Alison.Reid@curtin.edu.au.

Open access This is an open access article distributed in accordance with the Creative Commons Attribution Non Commercial (CC BY-NC 4.0) license, which permits others to distribute, remix, adapt, build upon this work non-commercially, and license their derivative works on different terms, provided the original work is properly cited, appropriate credit is given, any changes made indicated, and the use is non-commercial. See: http://creativecommons.org/licenses/by-nc/4.0/.

\section{ORCID iDs}

Alison Reid http://orcid.org/0000-0002-1202-7150

Alison Daly http://orcid.org/0000-0002-4919-5932 


\section{REFERENCES}

1 Daly A, Carey RN, Darcey E, et al. Workplace psychosocial stressors experienced by migrant workers in Australia: a cross-sectional study. PLoS One 2018;13:e0203998.

2 Fox S, Stallworth LE. Racial/ethnic bullying: exploring links between bullying and racism in the US workplace. $J$ Vocat Behav 2005;66:438-56.

3 Ronda Pérez E, Benavides FG, Levecque K, et al. Differences in working conditions and employment arrangements among migrant and non-migrant workers in Europe. Ethn Health 2012;17:563-77.

4 Campos-Serna J, Ronda-Pérez E, Artazcoz L, et al. Gender inequalities in occupational health related to the unequal distribution of working and employment conditions: a systematic review. Int $J$ Equity Health 2013;12:57.

5 Yao C, Thorn K, Duan Z, et al. Workplace stress in a foreign environment: Chinese migrants in New Zealand. Equal Div and Incl: An Int J 2015;34:608-21.

6 Goodboy AK, Martin MM, Knight JM, et al. Creating the boiler room environment: the job demand-control-support model as an explanation for workplace bullying. Commun Res 2015.

7 Janssens $H$, Braeckman L, De Clercq B, et al. The indirect association of job strain with long-term sickness absence through bullying: a mediation analysis using structural equation modeling. BMC Public Health 2016;16:851.

8 Karasek RA, Demands J, Latitude JD. Job demands, job decision latitude, and mental strain: implications for job redesign. Adm Sci Q 1979;24:285-308.

9 de Jonge J, Kompier MAJ. A critical examination of the demandcontrol-support model from a work psychological perspective. Int $J$ Stress Manag 1997;4:235-58.

10 Utzet M, Navarro A, Llorens C, et al. Intensification and isolation: psychosocial work environment changes in Spain 2005-10. Occup Med 2015;65:405-12.

11 Kivimäki M, Virtanen M, Elovainio M, et al. Work stress in the etiology of coronary heart disease--a meta-analysis. Scand J Work Environ Health 2006;32:431-42.

12 Mather L, Bergström G, Blom V, et al. High job demands, job strain, and iso-strain are risk factors for sick leave due to mental disorders: a prospective Swedish twin study with a 5-year follow-up. J Occup Environ Med 2015;57:858-65.

13 Amick BC, Kawachi I, Coakley EH, et al. Relationship of job strain and iso-strain to health status in a cohort of women in the United States. Scand J Work Environ Health 1998;24:54-61.

14 de Jonge J, van Vegchel N, Shimazu A, et al. A longitudinal test of the demand-control model using specific job demands and specific job control. Int J Behav Med 2010;17:125-33.

15 Lange S, Burr H, Conway PM, et al. Workplace bullying among employees in Germany: prevalence estimates and the role of the perpetrator. Int Arch Occup Environ Health 2019:92:237-47.

16 Einarsen S, Hoel H, Notelaers G. Measuring exposure to bullying and harassment at work: validity, factor structure and psychometric properties of the negative acts questionnaire-Revised. Work Stress 2009;23:24-44

17 Lamontagne AD, Smith PM, Louie AM, et al. Unwanted sexual advances at work: variations by employment arrangement in a sample of working Australians. Aust N Z J Public Health 2009;33:173-9.

18 Verkuil B, Atasayi S, Molendijk ML. Workplace bullying and mental health: a meta-analysis on cross-sectional and longitudinal data. PLoS One 2015;10:e0135225.

19 Tuckey MR, Dollard MF, Hosking PJ, et al. Workplace bullying: the role of psychosocial work environment factors. Int J Stress Manag 2009;16:215-32.

20 Nielsen MB, Einarsen S. Outcomes of exposure to workplace bullying: a meta-analytic review. Work Stress 2012;26:309-32.

21 Mundbjerg Eriksen TL, Hogh A, Hansen Åse Marie. Long-term consequences of workplace bullying on sickness absence. Labour Econ 2016;43:129-50.

22 Lahelma E, Lallukka T, Laaksonen M, et al. Workplace bullying and common mental disorders: a follow-up study. J Epidemiol Community Health 2012;66:e3.
23 Lewis D, Gunn ROD. Workplace bullying in the public sector: understanding the racial dimension. Public Adm 2007;85:641-65.

24 Schenker MB. Migration and occupational health: shining a light on the problem. Am J Ind Med 2010;53:327-8.

25 Australian Bureau of Statistics. Characteristics of recent migrants. Australia, Canberra: ACT, 2016

26 Productivity Commission. Migrant intake into Australia, inquiry report No. 77. Canberra, 2016.

27 Australian Bureau of Statistics. Census of population and housing. Canberra: Australian Bureau of Statistics, 2017.

28 Daly A, Carey RN, Darcey E, et al. Using three cross-sectional surveys to compare workplace psychosocial stressors and associated mental health status in six migrant groups working in Australia compared with Australian-born workers. Int J Environ Res Public Health 2019;16:735.

29 Australian Bureau of Statistics. Australian and New Zealand standard classification of occupations. 1 edn. Canberra: Australian Bureau of Statistics (ACT), 2016

30 Hosmer DW, Lemeshow S, Sturdivant RX. Applied logistic regression. 3 edn. New York, United States: John Wiley \& Sons, Incorporated, 2013.

31 Raftery AE. Bayesian model selection in social research. Sociol Methodol 1995;25:111-63.

32 Nielsen MB, Matthiesen SB, Einarsen S. The impact of methodological moderators on prevalence rates of workplace bullying. A meta-analysis. J Occup Organ Psychol 2010;83:955-79.

33 Vermeulen M, Mustard C. Gender differences in job strain, social support at work, and psychological distress. J Occup Health Psychol 2000;5:428-40.

34 Parent-Thirion A, Biletta I, Cabrita J, et al. Eurofound, sixth European working conditions survey-overview report. Luxembourg, 2017.

35 Potter RE, Dollard MF, Tuckey MR. Bullying \& harassment in Australian workplaces: results from the Australian workplace barometer project 2014/15. Canberra, ACT: Safe Work, Australia, 2016.

36 Zapf D, Escartín J, Einarsen S, et al. Empirical findings on prevalence and risk groups of bullying in the workplace. bullying and harassment in the workplace: developments in theory, research and practice, 2011.

37 Keashly L, Neuman JH. Destructive Organizational Communication: Processes, Consequences, and Constructive Ways of Organizing. In: Lutgen-Sandvik P, Davenport Sypher B, eds. Building a constructive communication climate: the workplace stress and aggression project. Routledge, 2009: 339-62.

38 Branch S, Ramsay S, Barker M, et al. Workplace bullying, mobbing and general harassment: a review. Int $J$ Manag Rev 2013;15:280-99.

39 Einarsen S. Harassment and bullying at work: a review of the scandinavian approach. Aggress Violent Behav 2000;5:379-401.

40 Escartín J, Salin D, Á R-C. Conceptualizations of workplace bullying: gendered rather than gender neutral? J Pers Psychol 2011:10:157-65.

41 Hutchinson J, Eveline J. Workplace bullying policy in the Australian public sector: why has gender been ignored? Aust J Public Adm 2010;69:47-60

42 Salin D. Risk factors of workplace bullying for men and women: the role of the psychosocial and physical work environment. Scand J Psychol 2015;56:69-77.

43 Goodboy AK, Martin MM, Bolkan S, et al. Workplace bullying and work engagement: a self-determination model. J Interpers Violence 2017:0886260517717492.

44 Niedhammer I, Milner A, LaMontagne AD, et al. Study of the validity of a job-exposure matrix for the job strain model factors: an update and a study of changes over time. Int Arch Occup Environ Health 2018;91:523-36.

45 Benach J, Vives A, Amable M, et al. Precarious employment: understanding an emerging social determinant of health. Annu Rev Public Health 2014;35:229-53.

46 Kretsos L, Livanos I. The extent and determinants of precarious employment in Europe. Int J Manpow 2016;37:25-43. 